\title{
COMPARATIVE STUDY OF THE PARALLEL AND ANGULAR ELECTRICAL GRIPPER FOR INDUSTRIAL APPLICATIONS
}

\author{
Mohammad Javad FOTUHI ${ }^{*}$, Zafer BINGUL ** \\ ${ }^{*}$ Research and Development, Keramik Makina Sanayi ve Ticaret A.S, \\ Güzeller Organize Sanayi Bölgesi İnönü Mah. Nursultan Nazarbayev Sok. No:21 41400 Gebze, Kocaeli, Turkey \\ "*Automation and Robotics Lab, Department of Mechatronics Engineering, Kocaeli University, \\ Kabaoğlu, Baki Komsuoğlu bulvarı No:515, Umuttepe, 41001 İmit/Kocaeli, Turkey \\ mohammad.fotuhi@keramik.com.tr, zaferb@kocaeli.edu.tr
}

received 22 October 2020, revised 25 May 2021, accepted 31 May 2021

\begin{abstract}
The aim of this paper is to study the position and power performances of an electrical lead screw-driven industrial gripper mechanism (LSDIGM). This work consists of designing and developing an electrical LSDIGM that has the potential to meet various demands in the automation industry and factories. The performances of both angular electrical gripper (AEG) and parallel electrical gripper (PEG) mechanisms were compared based on their position and power efficiency. The position efficiency of these electrical LSDIGM is computed from the position root mean square error (PRMSE) obtained from errors between the two measured positions (input incremental encoder and output linear encoder). In the experimental setup, a current sensor and a spring were employed to measure the current in the input of the system and the stiffness in the output of the system, respectively. The electrical power in the input of the electrical LSDIGM and the mechanical power in the output of the LSDIGMs were calculated using the current and the spring force, respectively. Finally, the power efficiency of these electrical LSDIGMs was examined and compared at different velocity circumstances.
\end{abstract}

Key words: Electrical lead screw-driven industrial gripper mechanism (LSDIGM), Efficiency, Position root mean square error (PRMSE), Parallel electrical gripper (PEG), Angular electrical gripper (AEG)

\section{INTRODUCTION}

Nowadays, designing and developing an inexpensive and reliable electric gripper mechanism in factories is very important in the robotic manufacturing revolution. In robotic systems, the gripper is like the human hand that allows one to grab and place any particular object. Grippers have been used in factories to facilitate various operations and for tasks that are dangerous and difficult for humans to perform, such as logistics, underwater welding, material handling, sensitive surgery, detecting and defusing bombs, and industrial furnaces (Birglen and Schlicht, 2018). The basic requirements of the gripper system design should be characterized as follows: high power/weight ratio giving the lowest machine mass, high torque/inertia ratio giving the best acceleration possible, the smooth trajectory of torque particularly at low speeds to minimize speed variation and achieve good positional accuracy, controlled torque at zero-speed, high maximum speed of operation, high efficiency and power factor to minimize drive requirement, compact integrated design with the application, good frequency response, low backlash, and low cost (Liu et al, 2020). To develop an industry interesting product, there is a need for inexpensive, simple, and robust solutions. Industrial robotic grippers have an effective role in modern automation as they constitute the end-of-arm of robotic manipulators and then, they are in direct contact with the work piece (Honarpardaz et al, 2017; Lu et al., 2019). Also, with the development of series elastic actuators and control methods, flexible grippers can be developed; flexible grippers have more accuracy of control and gripping force (Li et al., 2017). With the advent of modeling and simulation technology, design and development studies are increasingly focusing on robotics research. The key challenge in these problems is to find the right balance between all the conflicting goals. The perfect solution to an optimal design problem of a given gripper system is to develop a set of solutions by analyzing the system parameters that accomplish all the goals simultaneously (Kuang et al., 2017; Hu et al, 2019).

In a variety of industrial applications, hydraulic and pneumatic grippers are used to create a holding force according to specific specifications, depending on the load. However, hydraulic and pneumatic methods are not flexible and cannot be used in the manufacture of modern systems (Kumar et al., 2017). Today, a mechanical gripper in the system and mechatronics engineering are increasingly being replaced by electrically controlled drives called the electrical actuator (Tai et al., 2016). The electrical gripper is a mechanism used to perform linear motion electrically similar to that achieved with hydraulic and pneumatic grippers. In the main component of the electrical gripper, the classical mechanical gripper is replaced with an electrical motor and reprogrammable controller. Compared to the mechanical grippers, the electrical gripper improves accuracy and repeatability (Shin et al., 2012). The servomotors used in modern electrical grippers are well suited for complex motions because they are easy to control by changing the voltage and current, speed, and torque in the servomotors. However, motion systems using the feedback feature in these motors are expensive and quite complex. This is one of the main reasons why a stepper motor is used as an actuator 
in a proposed electronic gripper system while considering the low price and easy usage (Datta et al., 2015). A stepper motor is a motor that converts digital electric pulses into stepping mechanical movements. The most important advantage of a stepper motor is its use in an accurately open-loop control system. This type of control eliminates the need for expensive detection and feedback devices such as sensitive encoders. Its position is simply determined by tracking the input electrical pulses (Shaw and Dubey, 2016). The stepper motor can be a good selection for open-loop motion control. Stepper motors can be used in projects where rotation angle, speed, position, and synchronization must be controlled. Stepper motors can be used in many different projects (Su and Zhong, 2018). Because of these main advantages, a stepper motor is selected as an actuator for electromechanical gripper movement output in this paper. In this paper, the application of the lead screw-driven industrial gripper mechanism (LSDIGM) was developed from the switching of the existing pneumatic cylinder. The main goal of such a system is to avoid force overshoots in the contact stage while keeping stress force error in the high-sensitive tracking stage, where traditional pneumatic cylinders are not competent. The proposed method of the ratio of the maximum force (RMF) has been used to prove the appropriate force rate. In this study, the lead screw and electrical motor-driven industrial gripper mechanism model was developed to have a flexible and reprogrammable system. First, the design and modeling of electrical LSDIGM are briefly introduced. Then, the overall behavior structure of the system is proposed. The position and power efficiency of these electrical LSDIGMs were examined and compared at different velocity circumstances.

\section{MATERIALS AND METHODS}

In the case of rotational actuators, first, the movement forms have to be converted from rotational to linear movement. This can be achieved by a connecting lead screw to the actuator and a linear guide the diagram of the electrical LSDIGM is illustrated in Fig.1. For the electrical gripper, a model was developed in Li et al. (2011) and Chen et al. (2014). The mathematical model is based on two movements: the movement angle, $\theta$, to the motor angle and the movement distance to the load movement. The $\theta$ angle is linked by a lead-screw mechanism to the $d$ distance. The resultant angular motion and linear motion produce two respective forces: a lead-screw torsional torque $\tau_{\mathrm{ls}}$ applied at the input of the system and a gripper linear force $\mathrm{F}_{\mathrm{g}}$ applied at the output of the system.

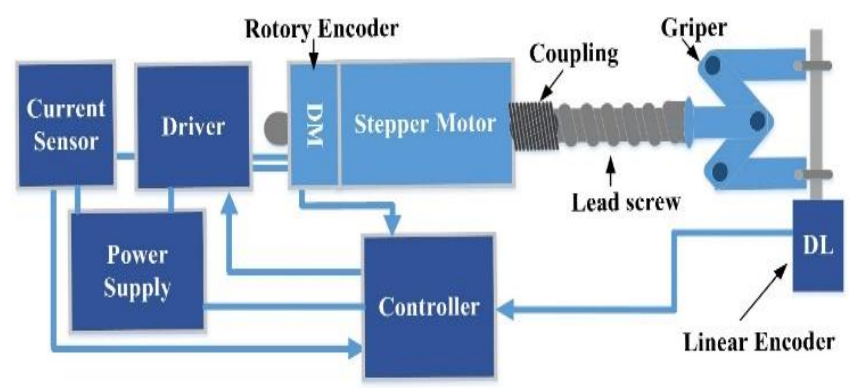

Fig. 1. Block diagram of the LSDIGM

In order to evaluate the performance of position errors, in general, the square root of the mean of all square errors (PRMSE) is calculated between the stepper motor position and the meas- ured load signal based on equation 1 (Chen et al., 2014; Nanda, 2010). The equations $(2,3,4,5)$ are used to illustrate the effect of time and position error in equation 1 .

PRMSE $\left.=\sqrt{\frac{1}{N} \sum_{i=1}^{N}\left(p_{i}-\hat{p}_{i}\right.}\right)^{2}$

Integral of the absolute value of the error (IAE):

$\mathrm{IAE}=\sum_{\mathrm{i}=1}^{\mathrm{N}}\left|\left(\mathrm{p}_{\mathrm{i}}-\hat{\mathrm{p}}_{\mathrm{i}}\right)\right|$

Integral of the square value of the error (ISE):

ISE $=\sum_{\mathrm{i}=1}^{\mathrm{N}}\left(\mathrm{p}_{\mathrm{i}}-\hat{\mathrm{p}}_{\mathrm{i}}\right)^{2}$ (ITAE):

Integral of the time-weighted absolute value of the error

ITAE $=\sum_{\mathrm{i}=1}^{\mathrm{N}} t\left|\left(\mathrm{p}_{\mathrm{i}}-\hat{\mathrm{p}}_{\mathrm{i}}\right)\right|$

Integral of the time-weighted square value of the error (ITSE):

$\operatorname{ITSE}=\sum_{\mathrm{i}=1}^{\mathrm{N}} t\left(\mathrm{p}_{\mathrm{i}}-\hat{\mathrm{p}}_{\mathrm{i}}\right)^{2}$

where $\mathrm{p}_{\mathrm{i}}$ is the output position, $\hat{\mathrm{p}}_{\mathrm{i}}$ is the input position, $t$ is the sampling time, and $N$ is the sampling number (Najjari et al., 2014).

In this paper, a standard algorithm using a C++ programming language is implemented in a Googoltech industrial PC to run the LSDIGM system. The stepper motor can be programmed and controlled in real-time by using this software via the output port of an industrial PC. In order to perform the gripper movement, the proposed method uses a lead screw for converting the rotary movement of the stepper motor into the linear movement.

\subsection{Mechanical Design}

To obtain a simple and inexpensive design, we minimized the amount of mechanical and electronic parts (Fig. 2). It was, therefore, decided to use a normal stepper motor and lead screw. Also, angular gripper and parallel gripper can be both opened and closed by only one HANPOSE 17HS3401S T8x8 Nema stepper motor with a PK6M05N lead screw driven by the stepper motor driver model CWD556 (Fig. 3). When a voltage of $24 \mathrm{~V}$ is applied to the motor, this results in a constant actuation torque of $0.5 \mathrm{Nm}$ applied at the base of the finger and $0.25 \mathrm{Nm}$ on each of the opposite fingers as defined (Park et al., 2016). First, it is required to determine the torque of the motor relative to the system's output force, the torque due to the force the load applies to the gripper finger called gripper force $\mathrm{F}_{\mathrm{g}}(\mathrm{N})$, and it is introduced through function $\mathrm{F}_{\mathrm{g}}$. The gripper force is given in equation (6) as mentioned before; for rotational actuators, the movement has to be converted from rotational to linear. To calculate the velocity of the motor, the linear speed of the gripper finger can be converted to rotational speed using equation (7).

$\mathrm{F}_{\mathrm{g}}=\frac{2 \pi \eta \tau_{1 s}}{\ell}$

$\mathrm{v}=\frac{\ell \omega}{2 \pi}$

where $F_{g}$ is the force/load applied $(N), \eta$ is the efficiency factor, $\omega$ is the rotational speed $(\mathrm{rad} / \mathrm{sec})$, and $v$ is the linear speed (mm/sec) (Liu et al., 2016). Torque $\tau_{\mathrm{ls}}$ is the lead-screw acting on the shaft caused by forces (see Fig. 4). It can be based on the following equations (8): 


\section{sciendo}

Mohammad Javad Fotuhi, Zafer Bingul

$\tau_{\mathrm{ls}}=\frac{\mathrm{F}_{\mathrm{a}} \mathrm{D}_{x}}{2}\left(\frac{\ell+\mu \pi \mathrm{D}_{x}}{\pi \mathrm{D}_{x}-\mu \mathrm{L}}\right)\left(\frac{1}{\eta}\right)$

where:

$\mathrm{D}_{x}=\mathrm{D}_{\mathrm{p}}-\left(\frac{\mathrm{P}_{\mathrm{B}}}{2}\right), \quad \ell=\mathrm{n}_{\mathrm{s}} \mathrm{P}_{\mathrm{B}}$

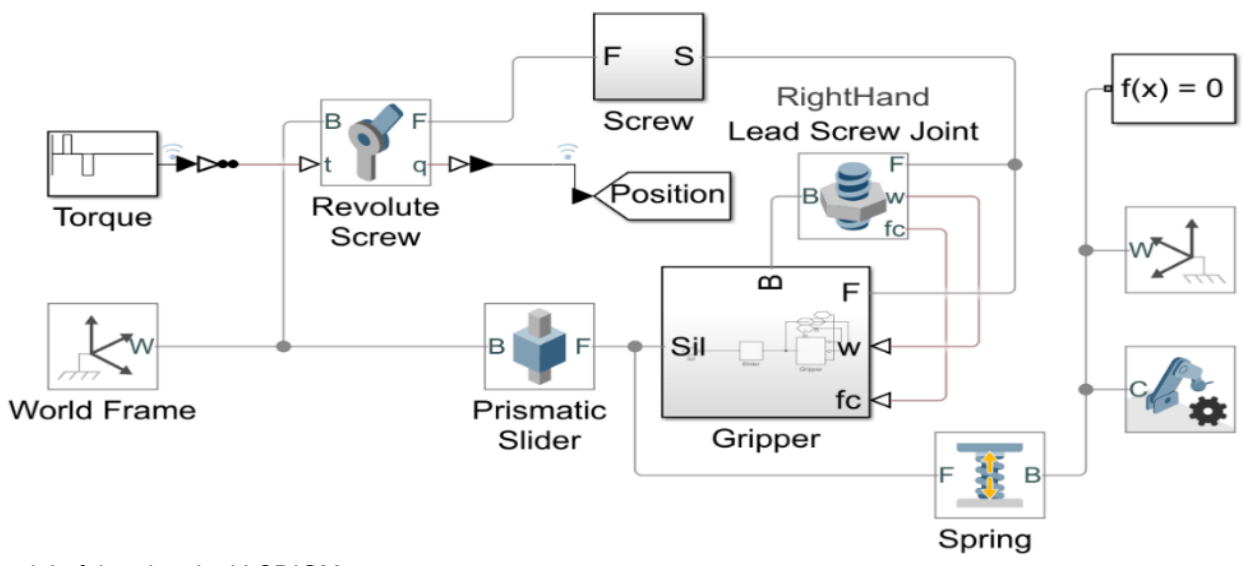

Fig. 2. Simscape model of the electrical LSDIGM actuator

$\mathrm{F}_{\mathrm{a}}$ is the moving force in the direction of the lead screw, and $\theta$ is the tilt angle (Xu et al., 2018; Hassan and Abomoharam, 2017). The parameters of the lead-screw model are given in Table 1.
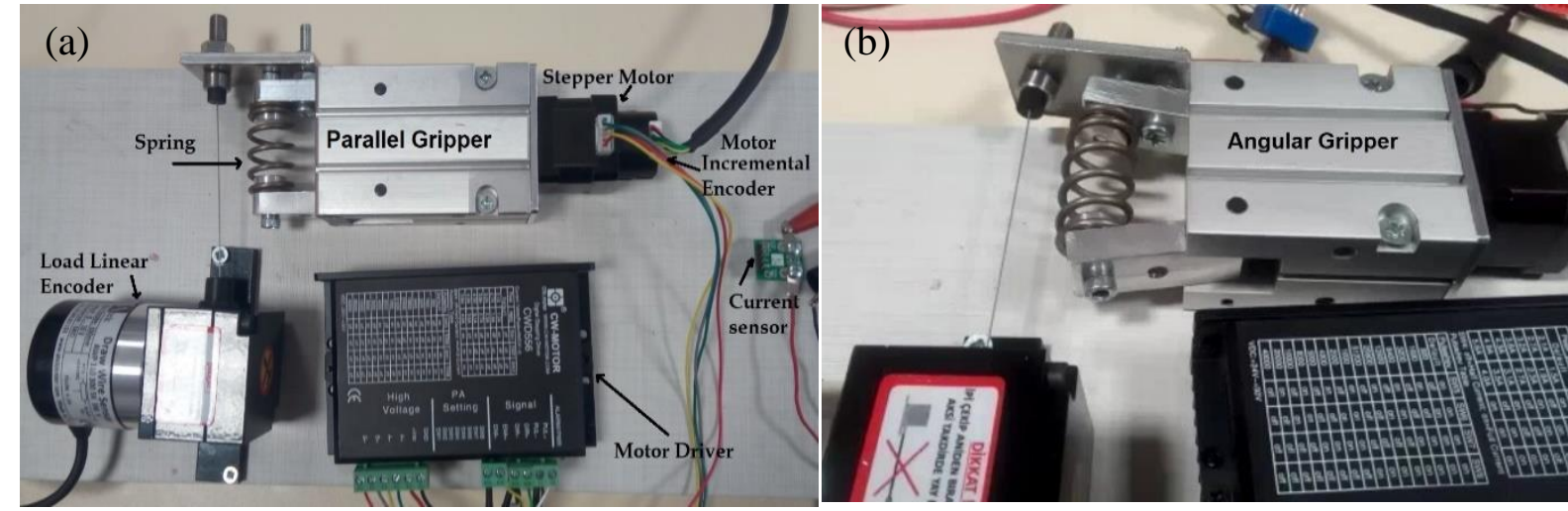

Fig. 3. Experimental setup of LSDIGM (a) parallel gripper and (b) angular gripper

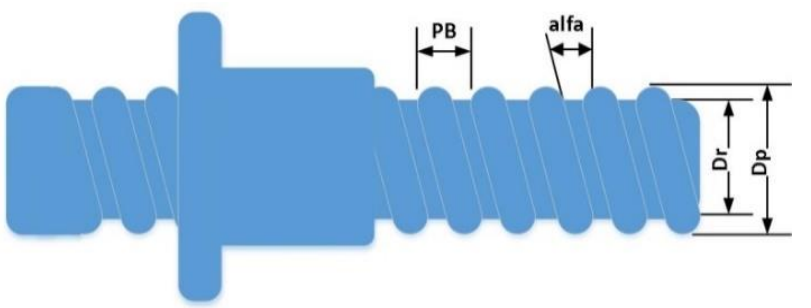

Fig. 4. Model of the lead screw

Tab. 1. Parameters of lead-screw model-PK6M05N

\begin{tabular}{|c|c|c|}
\hline Parameter & Symbol & Value \\
\hline Pitch circle diameter & $\mathrm{D}_{\mathrm{p}}$ & $9.5 \mathrm{~mm}$ \\
\hline Screw pitch & $\mathrm{P}_{\mathrm{B}}$ & $5 \mathrm{~mm}$ \\
\hline Lead of the thread & $\ell$ & $5 \mathrm{~mm}$ \\
\hline The starts number & $\mathrm{n}_{\mathrm{s}}$ & 1 \\
\hline $\begin{array}{c}\text { Friction coefficient of sliding } \\
\text { surface }\end{array}$ & $\mu$ & 0.15 \\
\hline Thread angle & $\mathrm{A}$ & 30 degree \\
\hline
\end{tabular}

\subsection{Modeling of Electromechanical System}

To analyze the dynamic characteristics after the completion of the development of the electromechanical system, an electrical LSDIGM actuator model was created in SIMULINK ${ }^{\mathrm{TM}}$ (Fig. 2).

Contributions from the different system variables were combined to simplify the model. The motor rotor inertia, screw nut inertia, and carrier inertia were combined, along with the referred inertial contribution from the linear motion parts and were represented by equation (10).

$\mathrm{J}_{\text {tot }}=\mathrm{J}_{\text {motor }}+\mathrm{J}_{\text {nut }}+\mathrm{J}_{\text {carrier }}+\mathrm{m}\left(\frac{\mathrm{L}}{2 \pi}\right)^{2}$

where $m$ is the mass of the linear components, and $\ell$ is the screw lead. This leads to

$$
\begin{aligned}
& \mathrm{J}_{\text {tot }} \alpha=\tau_{\text {motor }}-\left(\tau_{\text {load }}+\tau_{\text {viscous }}+\tau_{\text {Coulomb }}\right) \\
& \mathrm{J}_{\text {tot }} \frac{\mathrm{d}^{2} \theta}{\mathrm{d} t^{2}}=\tau_{\text {motor }}-\left(F_{g} X+\beta \frac{\mathrm{d} \theta}{\mathrm{d} t}-\mathrm{F}_{c} \frac{\frac{\mathrm{d} \theta}{\mathrm{d} t}}{\left|\frac{\mathrm{d} \theta}{\mathrm{d} t}\right|}\right)
\end{aligned}
$$


where $\mathrm{F}_{\mathrm{g}}$ is the force on the gripper fingers, $j$ represents the gear ratio and linear conversion, $\beta$ represents the viscous damping coefficient, and $F_{\mathrm{c}}$ represents the Coulomb force component.

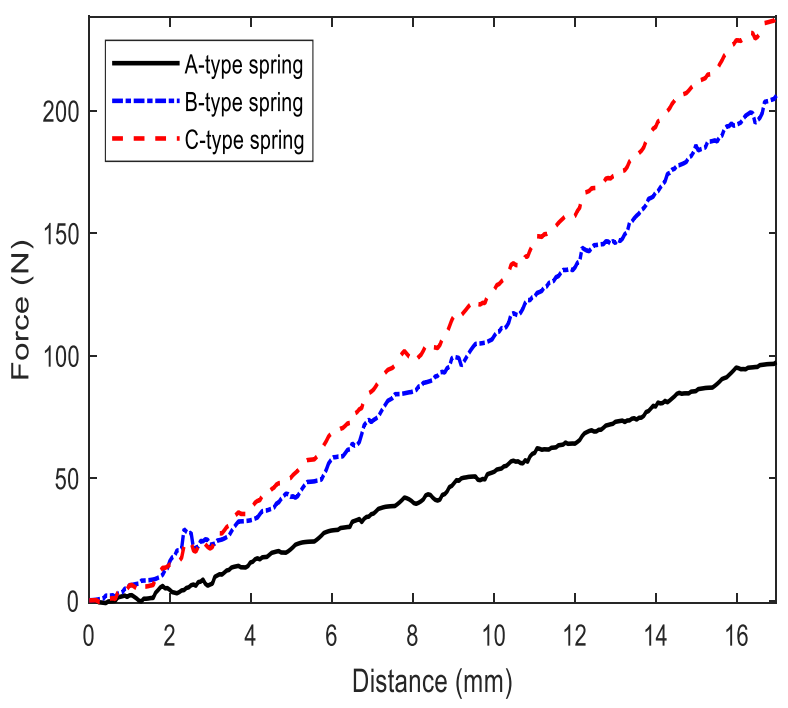

Fig. 5. Force-distance (stiffness) characteristic of the springs given in Table 3

\section{RESULTS AND DISCUSSION}

There are several methods for analyzing and measuring force, three springs with different stiffness coefficient values (Fig. 5 and Table 3) have been used to analyze the dynamic behavior of the system (Fotuhi et al., 2020). To analyze the gripper, two sensors were used to measure data. Sensors are incremental encoders of motor and linear encoders of load (Fotuhi and Bingul, 2021; Wang et al., 2016). Motor incremental encoder gives a pulse output of 0.17578125 (degrees/pulse), and load linear encoder gives a voltage output of $0.5(\mathrm{mV} / \mathrm{mm})$. Over the range $0-20 \mathrm{~mm}$, this is amplified by an amplifier with a voltage gain of 20 , sampled, and applied to a 10-bit analog-to-digital converter with voltage range $0-5 \mathrm{~V}$. The resolution of the measurement is 1024 (digital val$\mathrm{ue} / \mathrm{mm}$ ). The experimental setup of electrical LSDIGM is shown in Fig. 3. The position and current analog signals are converted to physical parameters by using sensor gains (equations 13,14 , and 15). They are given in Table 2.

$$
\begin{aligned}
& \mathrm{D}_{\mathrm{L}}(\mathrm{mm})=\left(\mathrm{V}_{\mathrm{L}}-\mathrm{o}_{\mathrm{V}}\right) *\left(\mathrm{c}_{\mathrm{V}}\right) \\
& \mathrm{D}_{\mathrm{M}}(\mathrm{mm})=\left(\mathrm{P}_{\mathrm{M}}-\mathrm{o}_{\mathrm{p}}\right) *\left(\mathrm{c}_{\mathrm{P}}{ }^{-1}\right) \\
& \mathrm{C}_{\mathrm{S}}(\text { Amper })=\left(\mathrm{V}_{\mathrm{c}}-\mathrm{o}_{\mathrm{c}}\right) *\left(\mathrm{c}_{\mathrm{c}}{ }^{-1}\right)
\end{aligned}
$$

here, $D_{L}$ is the distance of load $(\mathrm{mm}), D_{M}$ is the distance of linear movement of motor $(\mathrm{mm}), C_{S}$ is the equation of current sensing, $V_{L}$ is the digitized voltage from analog to digital using an ADC (analog-to-digital converter) value of voltage output of the load linear encoder (digital value), $P_{M}$ is the pulse number of the motor incremental encoder (pulse), and $V_{c}$ is the discrete voltage (ADC value of voltage) output of the current sensor.
Tab. 2. Position and current sensor gains

\begin{tabular}{|c|c|c|}
\hline $\begin{array}{c}\text { Parameter } \\
\begin{array}{c}\text { Voltage coefficient of the linear } \\
\text { encoder }\end{array}\end{array}$ & $\mathrm{c}_{\mathrm{V}}$ & 1.427428571 \\
\hline $\begin{array}{c}\text { Pulse coefficient of the incremental } \\
\text { encoder }\end{array}$ & $\mathrm{c}_{\mathrm{P}}$ & 1.0058 \\
\hline $\begin{array}{c}\text { Current coefficient of the current } \\
\text { sensor }\end{array}$ & $\mathrm{c}_{\mathrm{c}}$ & 29.457 \\
\hline Offset of voltage & $\mathrm{o}_{\mathrm{v}}$ & 779.7638571 \\
\hline Offset of pulse & $\mathrm{o}_{\mathrm{p}}$ & 62.41924891 \\
\hline Offset of current & $\mathrm{o}_{\mathrm{c}}$ & 17.92554531 \\
\hline
\end{tabular}

Tab. 3. Technical specification of springs

\begin{tabular}{|c|c|c|c|c|}
\hline $\begin{array}{c}\text { Spring } \\
\text { type }\end{array}$ & $\begin{array}{c}\text { Stiffness }(\text { Ks } \\
\mathbf{=} \mathbf{N} / \mathbf{m m})\end{array}$ & $\begin{array}{c}\text { Free length } \\
(\mathbf{m m})\end{array}$ & $\begin{array}{c}\text { Full compres- } \\
\text { sion }(\mathbf{m m})\end{array}$ & $\begin{array}{c}\text { Total } \\
\text { coil }\end{array}$ \\
\hline A & 5.735 & 42.1 & 25.3 & 7 \\
\hline B & 11.764 & 42.5 & 25.2 & 7 \\
\hline C & 13.823 & 42.2 & 25.6 & 7 \\
\hline
\end{tabular}

Tab. 4. Velocity profile (maximum speed $=30 \mathrm{~mm} / \mathrm{sec}$ )

\begin{tabular}{|c|c|c|}
\hline Speed mode & Speed & Speed $(\mathrm{mm} / \mathbf{s e c})$ \\
\hline Low speed (LS) & $5 \%$ Max & 1.5 \\
\hline Medium speed (MS) & $20 \%$ Max & 6 \\
\hline High speed (HS) & $65 \%$ Max & 19.5 \\
\hline Very high speed (VHS) & $85 \%$ Max & 25.5 \\
\hline
\end{tabular}

To avoid repetition of showing the same behavior in the paper, the movement profile of a parallel and angular gripper A-type of the spring in the low-speed case is only illustrated in Fig. 6 . The results of the medium, high, and very high speed of B-type and Ctype of springs for parallel and angular gripper are given also in Tables 5 and 6 . The velocity profile is shown in Table 4.

According to Table 5, for the A-type spring, the maximal force of $106.4 \mathrm{~N}$ and the maximum linear movement of $18.55 \mathrm{~mm}$ are obtained by the high velocity of $5.892 \mathrm{~mm} / \mathrm{sec}$. For the B-type spring, the maximal force of $100 \mathrm{~N}$ and the maximum linear movement of $9 \mathrm{~mm}$ are obtained by the high velocity of 1.375 $\mathrm{mm} / \mathrm{sec}$. For the C-type spring, the maximal force of $105 \mathrm{~N}$ and the maximum linear movement of $8.013 \mathrm{~mm}$ are obtained by the high velocity of $1.375 \mathrm{~mm} / \mathrm{sec}$. According to Table 6 , for the Atype spring, the maximal force of $65.36 \mathrm{~N}$ and the maximum linear movement of $11.55 \mathrm{~mm}$ are obtained by the high velocity of 1.378 $\mathrm{mm} / \mathrm{sec}$. For the B-type spring, the maximal force of $84.86 \mathrm{~N}$ and the maximum linear movement of $6.966 \mathrm{~mm}$ are obtained by the high velocity of $1.375 \mathrm{~mm} / \mathrm{sec}$. For the C-type spring, the maximal force of $103.7 \mathrm{~N}$ and the maximum linear movement of $7.504 \mathrm{~mm}$ are obtained by the high velocity of $1.371 \mathrm{~mm} / \mathrm{sec}$.

According to Table 7 , equations (2, 3, 4, and 5) are used to illustrate the effect of time and position error in equation (1). 
Mohammad Javad Fotuhi, Zafer Bingul

Comparative Study of the Parallel and Angular Electrical Gripper for Industrial Applications
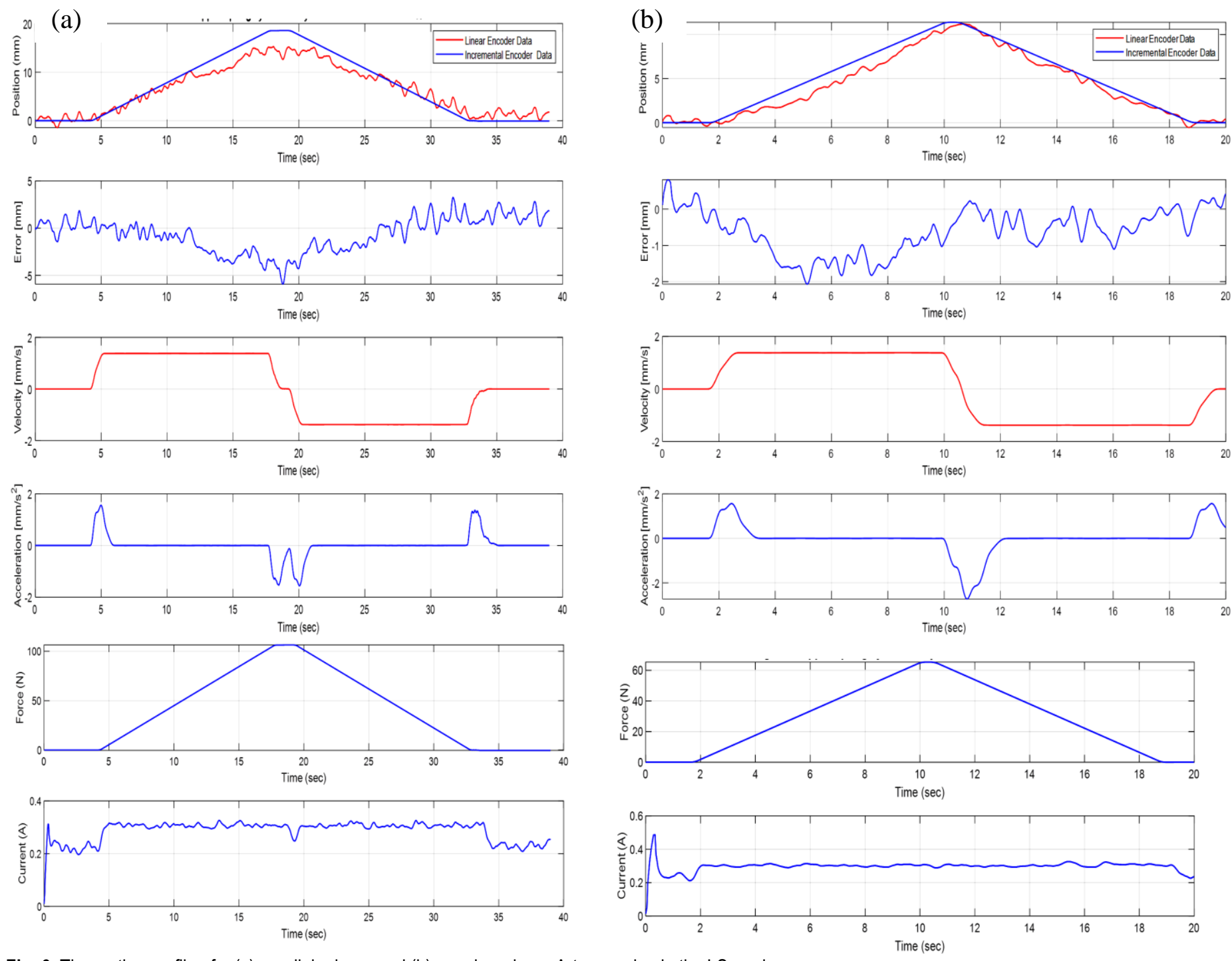

Fig. 6. The motion profile of a (a) parallel gripper and (b) angular gripper A-type spring in the LS mode

Tab. 5. Parallel gripper and spring motion analysis

\begin{tabular}{c|ccccccc} 
Spring type & Speed mode & $\begin{array}{c}\text { Maximum linear } \\
\text { movement } \\
(\mathbf{m m})\end{array}$ & $\begin{array}{c}\text { Maximum } \\
\text { force }(\boldsymbol{N})\end{array}$ & $\begin{array}{c}\text { Time } \\
(\mathbf{s e c})\end{array}$ & $\begin{array}{c}\text { Maximum } \\
\text { current } \\
(\boldsymbol{A})\end{array}$ & $\begin{array}{c}\text { Maximum } \\
\text { velocity } \\
(\mathbf{m m} / \mathbf{s e c})\end{array}$ & $\begin{array}{c}\text { Maximum } \\
\text { acceleration } \\
\left(\mathbf{m m} / \mathbf{s e c}^{2}\right)\end{array}$ \\
\hline \multirow{2}{*}{$\boldsymbol{A}$} & LS & 18.54 & 106.4 & 28.869 & 0.3155 & 1.376 & 1.547 \\
& MS & 18.51 & 106.3 & 8.79 & 0.3150 & 5.892 & 6.598 \\
& HS & 17.26 & 103.73 & 3.735 & 0.3399 & 18.88 & 22.24 \\
\hline \multirow{3}{*}{ B } & VHS & 6.085 & 34.9 & 4.26 & 0.3106 & 9.991 & 19.75 \\
\hline & LS & 9.09 & 106 & 13.49 & 0.7168 & 1.375 & 1.523 \\
& MS & 8.934 & 105.1 & 9.675 & 0.3161 & 5.889 & 6.336 \\
& HS & 8.934 & 105.1 & 4.59 & 0.3228 & 12.34 & 18.22 \\
& VHS & 2.827 & 33.26 & 6.21 & 0.3088 & 5.179 & 9.689 \\
\hline & LS & 8.013 & 105 & 14.45 & 0.3129 & 1.376 & 1.553 \\
& MS & 8.0 & 104 & 7.755 & 0.3045 & 5.887 & 6.667 \\
& HS & 7.864 & 101.1 & 3.38 & 0.3203 & 11.12 & 17.82
\end{tabular}


Tab. 6. Angular gripper and spring motion analysis

\begin{tabular}{|c|c|c|c|c|c|c|c|}
\hline Spring type & Speed mode & $\begin{array}{c}\text { Maximum linear } \\
\text { movement } \\
(\mathrm{mm})\end{array}$ & $\begin{array}{c}\text { Maximum } \\
\text { force (N) }\end{array}$ & $\begin{array}{l}\text { Time } \\
\text { (sec) }\end{array}$ & $\begin{array}{c}\text { Maximum } \\
\text { current } \\
\text { (A) }\end{array}$ & $\begin{array}{c}\text { Maximum } \\
\text { velocity } \\
(\mathrm{mm} / \mathrm{sec})\end{array}$ & $\begin{array}{l}\text { Maximum } \\
\text { acceleration } \\
\left(\mathrm{mm} / \mathrm{sec}^{2}\right)\end{array}$ \\
\hline \multirow[t]{4}{*}{$A$} & LS & 11.4 & 65.36 & 17.525 & 0.4862 & 1.378 & 1.561 \\
\hline & MS & 11.4 & 65.36 & 8.04 & 0.3203 & 5.887 & 6.682 \\
\hline & HS & 7.28 & 55.1 & 4.275 & 0.3176 & 11.74 & 17.94 \\
\hline & VHS & 5.047 & 28.94 & 2.565 & 0.2941 & 8.848 & 16.75 \\
\hline \multirow[t]{4}{*}{$B$} & LS & 6.966 & 84.86 & 14.355 & 0.3765 & 1.375 & 1.528 \\
\hline & MS & 6.611 & 79.27 & 3.51 & 0.3105 & 5.883 & 7.712 \\
\hline & HS & 6.362 & 74.84 & 2.37 & 0.322 & 9.028 & 15.96 \\
\hline & VHS & 4.137 & 48.67 & 44.087 & 0.3099 & 13.24 & 53.43 \\
\hline \multirow[t]{4}{*}{$C$} & LS & 7.504 & 103.7 & 20.7 & 0.3033 & 1.371 & 1.495 \\
\hline & MS & 7.144 & 101.7 & 5.13 & 0.3094 & 5.886 & 6.586 \\
\hline & $\mathrm{HS}$ & 6.847 & 98.21 & 3.386 & 0.3081 & 10.763 & 17.16 \\
\hline & VHS & 3.714 & 51.32 & 2.40 & 0.3071 & 6.264 & 11.45 \\
\hline
\end{tabular}
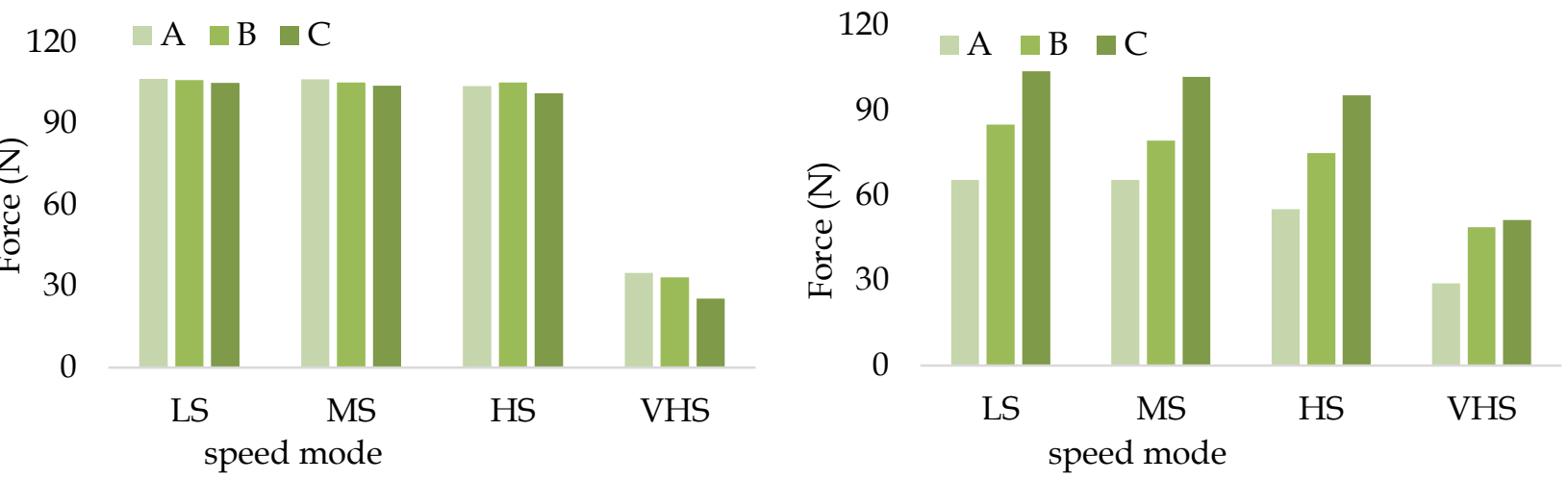

Fig. 7. (a) Parallel and (b) angular gripper spring force analysis. Note: A-type, B-type, and C-type spring

Tab. 7. RMS position error (ISE method) comparison of different speed cases (unit: mm). Note: A-type, B-type and C-type spring

\begin{tabular}{|c|c|c|c|c|c|c|}
\hline \multirow{2}{*}{$\begin{array}{c}\text { Speed } \\
\text { mode }\end{array}$} & \multicolumn{3}{|c|}{ Parallel gripper } & \multicolumn{3}{c|}{ Angular gripper } \\
\cline { 2 - 7 } & A & B & C & A & B & C \\
\hline LS & 0.0113 & 0.0199 & 0.0110 & 0.0557 & 0.0350 & 0.0117 \\
\hline MS & 0.0146 & 0.0323 & 0.0151 & 0.0784 & 0.0554 & 0.0354 \\
\hline HS & 0.0266 & 0.0379 & 0.0273 & 0.1177 & 0.0847 & 0.0473 \\
\hline VHS & 0.0260 & 0.0140 & 0.0085 & 0.0280 & 0.3765 & 0.0610 \\
\hline
\end{tabular}

(a)

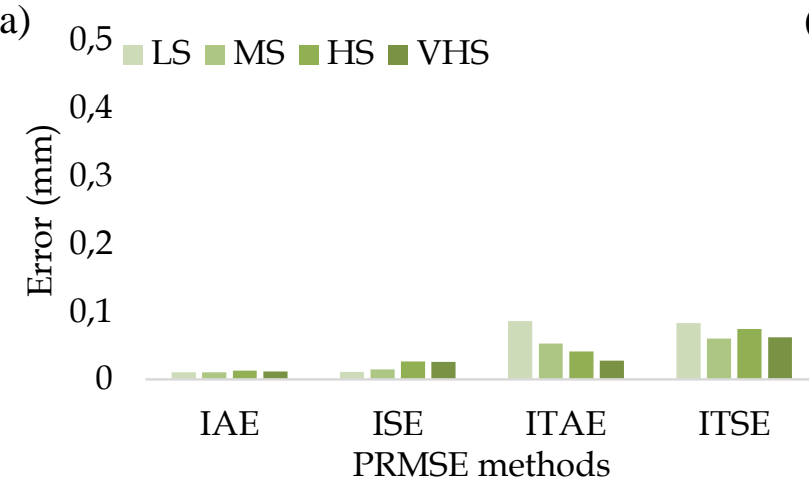

(b) 0,5

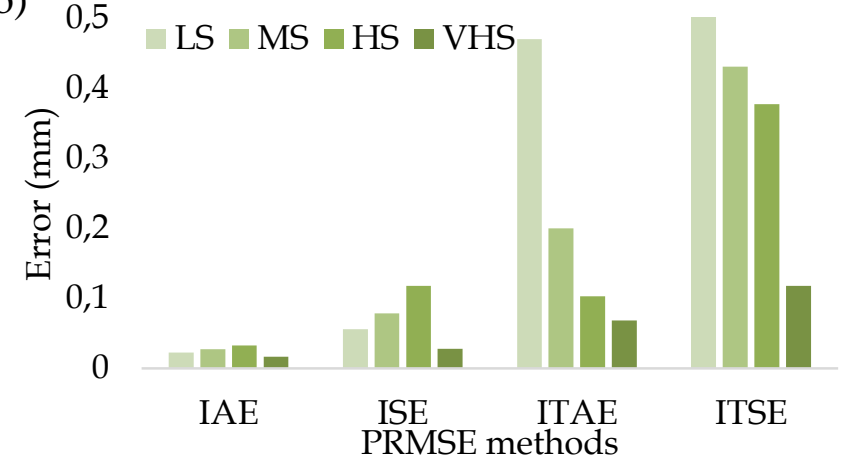

Fig. 8. The PRMSEs of different speed cases with A-type spring: (a) parallel gripper and (b) angular gripper 
To evaluate the performance of the maximum force of the electrical LSDIGM, the ratio of the maximum force (RMF) between the desirable force $\left(F_{d}\right)$ and the measured force $\left(F_{m}\right)$ of the system is calculated based on the following equation (16) (Varanasi and Nayfeh, 2004). These ratios are given in Tables 8 and 9 . The RMF is the highest ratio of the force applied by the system to the spring.

$\operatorname{RMF}=\left(1-\left(\frac{F_{d}-F_{m}}{F_{d}}\right)\right) * 100$

Tab. 8. The highest ratio of the force applied-PEG

\begin{tabular}{|c|c|c|c|}
\hline \multirow{2}{*}{$\begin{array}{c}\text { Speed } \\
\text { mode }\end{array}$} & \multicolumn{3}{|c|}{ Spring type } \\
\cline { 2 - 4 } & A & B & C \\
\hline LS & 92.52 & 92.17 & 92.45 \\
\hline MS & 92.43 & 91.39 & 92.27 \\
\hline HS & 90.20 & 91.39 & 86.55 \\
\hline VHS & 30.35 & 44.25 & 46.65 \\
\hline
\end{tabular}

The highest ratio of the force applied by the system to the Atype spring is $92.52 \%$ obtained by the low velocity of $1.376 \mathrm{~mm} / \mathrm{s}$. It can be seen that in Table 8 the lowest values are related to the fourth row of speeds (VHS) that are less than $50 \%$ and the values are unacceptable, indicating that the system did not respond correctly at this speed (Heilala et al., 1992; Pham and Yeo, 1991).

Tab. 9. The highest ratio of the force applied-AEG

\begin{tabular}{|c|c|c|c|}
\hline \multirow{2}{*}{$\begin{array}{c}\text { Speed } \\
\text { mode }\end{array}$} & \multicolumn{3}{|c|}{ Spring type } \\
\cline { 2 - 4 } & A & B & C \\
\hline LS & 59.42 & 77.15 & 91.30 \\
\hline MS & 59.42 & 72.06 & 90.43 \\
\hline HS & 50.09 & 68.04 & 87.91 \\
\hline VHS & 26.31 & 28.92 & 22.07 \\
\hline
\end{tabular}

The highest ratio of the force applied by the system to the Ctype spring is $92.45 \%$ obtained by the low velocities of 1.495 $\mathrm{mm} / \mathrm{s}$. It can be seen that in Table 9 the lowest values are related to the fourth row of speeds (VHS) that are less than $50 \%$ and the values are unacceptable, indicating that the system did not respond correctly at this speed. According to Tables 4 and 5 , and applying speeds from Tables 8 and 9 , the highest power for the parallel gripper is 1.96 watt (A- HS) and for the angular gripper is 1.06 watt (C- HS), respectively.

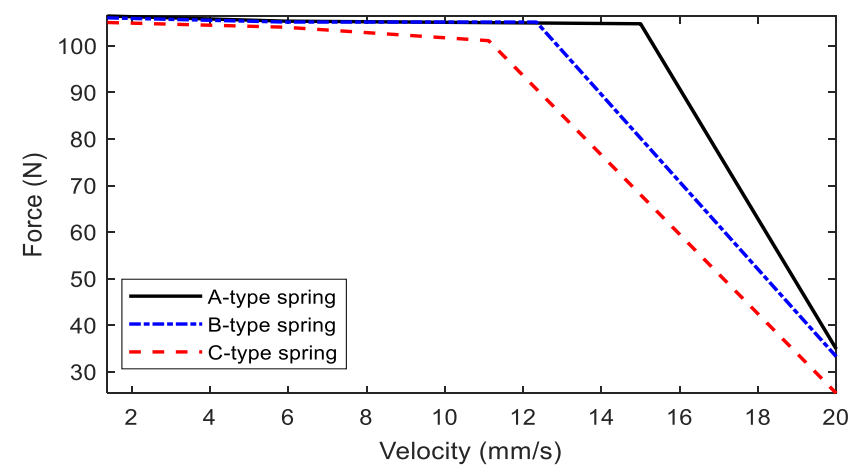

Fig. 9. Velocity-force characteristics
For three springs with different stiffness coefficient values, the force analysis of two different grippers (parallel and angular) is illustrated in Fig. 7. Fig. 8 shows comparison of the position error of the grippers with A-type spring in different speed cases. As can be seen in Fig. 9 (taken from the data in Table 5), the output force of the parallel gripper is nearly constant with $105 \mathrm{~N}$ at the velocities of between 1.5 and $12 \mathrm{~mm} / \mathrm{sec}$. This relationship between force and speed can be seen in Figs. 7, 8 and 9. The best angular gripper efficiency with a spring stiffness of 11.764 at a velocity of $1.5 \mathrm{~mm} / \mathrm{sec}$, which is $29 \%$, and the best parallel gripper efficiency with a spring stiffness of 5.735 at a velocity of $1.5 \mathrm{~mm} / \mathrm{s}$, which is $52 \%$.

\section{CONCLUSION}

In this paper, design and force-velocity performance analysis of the electrical gripper mechanism were examined. In this work, a stepper motor and a lead-screw mechanism were used for an inexpensive gripper as an industrial product. In order to test the performance of the system, an analysis of the LSDIGM, experimental setup with springs and encoders were arranged. The performance of the grippers is dependent on position and power efficiency. The LSDIGMs were tested with different springs and velocity profiles to obtain these efficiencies. The results show that the electrical parallel gripper performed better than the electrical angular gripper, and the highest ratio of the force applied by the proposed parallel gripper is $92.52 \%$ at $1.376 \mathrm{~mm} / \mathrm{sec}$. Although the proposed method has a very small (low) position error (accuracy) due to the operating characteristics of the stepper motor, it is simpler and less expensive than its counterparts. Therefore, it may be preferred for some applications where minor position errors are not important. Using the proper stepper motor (high power and high position accuracy) and the lead screw, these position errors occurred here may be eliminated very easily.

\section{REFERENCES}

1. Birglen L., Schlicht, T. (2018), A statistical review of industrial robotic grippers., Robotics and Computer-Integrated Manufacturing, 49, 88-97.

2. Chen Z., Xu J., Yu L., Xiong Y., Zhu H. (2014, May), Design and implementation of the electric gripper control system based on the DSP. In The 26th Chinese Control and Decision Conference (2014 CCDC), (pp. 3513-3517, ). IEEE.

3. Datta R., Pradhan S., Bhattacharya B. (2015), Analysis and design optimization of a robotic gripper using multiobjective genetic algorithm. , IEEE Transactions on Systems, Man, and Cybernetics: Systems, 46(1), 16-26.

4. Fotuhi M. J., Bingul Z. (2021), Fuzzy torque trajectory control of a rotary series elastic actuator with nonlinear friction compensation. , ISA transactions.

5. Fotuhi M. J., \& Bingul Z. (2021), Novel fractional hybrid impedance control of series elastic muscle-tendon actuator. , Industrial Robot: the international journal of robotics research and application.

6. Fotuhi M. J., Yılmaz O., Bingul Z. (2020), Human postural ankle torque control model during standing posture with a series elastic muscle-tendon actuator., SN Applied Sciences, 2(2), 1-8.

7. Hassan A., Abomoharam M. (2017), Modeling and design optimization of a robot gripper mechanism. , Robotics and ComputerIntegrated Manufacturing, 46, 94-103.

8. Heilala J., Ropponen T., \& Airila M. (1992), Mechatronic design for industrial grippers. , Mechatronics, 2(3), 239-255. 
9. Honarpardaz M., Tarkian M., Ölvander J., Feng X. (2017), Finger design automation for industrial robot grippers: A review. , Robotics and Autonomous Systems, 87, 104-119.

10. Hu Z., Wan W., Harada K. (2019), Designing a mechanical tool for robots with two-finger parallel grippers., IEEE Robotics and Automation Letters, 4(3), 2981-2988.

11. Kuang L., Lou Y., Song S. (2017), Design and fabrication of a nove force sensor for robot grippers., IEEE Sensors Journal, 18(4), 1410-1418

12. Kumar R., Mehta U., Chand P. (2017), A low cost linear force feedback control system for a two-fingered parallel configuration gripper. , Procedia computer science, 105, 264-269.

13. Li Q. M., Qin Q. H., Zhang S. W., Deng H. (2011), Optimal design for heavy forging robot grippers. , In Applied Mechanics and Materials (Vol. , 44, pp. 743-747). , Trans Tech Publications Ltd.

14. Li X., Chen W., Lin W., Low K. H. (2017), A variable stiffness robotic gripper based on structure-controlled principle. , IEEE Transactions on Automation Science and Engineering, 15(3), 11041113.

15. Liu C. H., Chung F. M., Chen Y., Chiu C. H., Chen T. L. (2020), Optimal Design of a Motor-Driven Three-Finger Soft Robotic Gripper., IEEE/ASME Transactions on Mechatronics, 25(4), 18301840.

16. Liu Y., Zhang Y., Xu Q. (2016), Design and control of a novel compliant constant-force gripper based on buckled fixed-guided beams. , IEEE/ASME Transactions on Mechatronics, 22(1), 476-486.

17. Lu, Y., Xie , Z., Wang, J., Yue, H., Wu, M., \& Liu, Y. (2019), A novel design of a parallel gripper actuated by a large-stroke shape memory alloy actuator., International Journal of Mechanical Sciences, 159, 74-80.

18. Najjari B., Barakati S. M., Mohammadi A., Futohi M. J., Bostanian M. (2014), Position control of an electro-pneumatic system based on PWM technique and FLC. , ISA transactions, 53(2), 647-657.

19. Nanda A. P. (2010), Design \& Development of a Two-jaw parallel Pneumatic Gripper for Robotic Manipulation (Doctoral dissertation).
20. Park T. M., Won S. Y., Lee S. R., Sziebig G. (2016, June), Force feedback based gripper control on a robotic arm. In, 2016 IEEE 20th Jubilee International Conference on Intelligent Engineering Systems (INES), (pp. 107-112, ). IEEE.

21. Pham D. T., Yeo S. H. (1991), Strategies for gripper design and selection in robotic assembly. The International Journal of Production Research, 29(2), 303-316.

22. Shaw J. S., Dubey V. (2016, August), Design of servo actuated robotic gripper using force control for range of objects. , In 2016 International Conference on Advanced Robotics and Intelligent Systems (ARIS) (pp. 1-6). ), IEEE.

23. Shin D. H., Park T. S., Jeong C. P., Kim Y. G., An J. N. (2012), Study of torsion spring's parameters with angular type grippers. In Advanced Materials Research (Vol. , 502, pp. 355-359). .Trans Tech Publications Ltd.

24. Su K. H., Zhong Y. H. (2018, July), Design of Handling Gripper and its Application to Smart Pet Robot. , In 2018 International Conference on Machine Learning and Cybernetics (ICMLC) (Vol. , 1, pp. 105-108). IEEE..

25. Tai K., El-Sayed A. R., Shahriari M., Biglarbegian M., Mahmud S. (2016), State of the art robotic grippers and applications., Robotics, 5(2), 11.

26. Varanasi K. K., \& Nayfeh S. A. (2004), The dynamics of lead-screw drives: low-order modeling and experiments. , J. Dyn. Sys., Meas., Control, 126(2), 388-396.

27. Wang X., Xiao Y., Fan X., \& Zhao Y. (2016, May), Design and grip force control of dual-motor drive electric gripper with parallel fingers. , In 2016 IEEE Information Technology, Networking, Electronic and Automation Control Conference, (pp. 696-700, ). IEEE.

28. Xu F., Wang B., Shen J., Hu J., Jiang G. (2018), Design and realization of the claw gripper system of a climbing robot. , Journal of Intelligent \& Robotic Systems, 89(3), 301-317. 